14. Reardon, P. O., L. B. Merrill, and C. A. Taylor, Jr. 1978. White-tailed deer preferences and hunter success under various grazing systems. Journal of Range Management 31:40-42.

15. Short, J. J., And J. E. Knight. 2003. Fall grazing affects big game forage on rough fescue grasslands. Journal of Range Management 56:213-217.

16. Crane, K. K., J. C. Mosley, T. K. Brewer, W.L.F. Torstenson, and M. W. Tess. 2001. Influence of cattle grazing on elk habitat selection. Proceedings of the Western Section of the American Society of Animal Science; 20-23 June 2001; Bozeman, MT, USA. 5 p.
17. Clark, P. E., W. C. Krueger, L. D. Bryant, and D. R. Thomas. 2000. Livestock grazing effects on forage quality of elk winter range. Journal of Range Management 53:97-105.

Authors are Graduate Fellow, King Ranch Institute for Ranch Management, Texas AEऽM University-Kingsville, Kingsville, TX 78363, USA, ksaha01@tamuk.edn (Anderson); and Assistant Professor, King Ranch Institute for Ranch Management, Texas AEऽM University-Kingsville, Kingsville, TX 78363, USA (McCuistion).

\title{
Interpreting and Measuring Indicators of Rangeland Health
}

\section{3-16 May: Las Cruces, New Mexico BLM Course 10-13 June: Worland, Wyoming}

Content (50\% field, same for both sessions, Tuesday 8:00 AM - Friday 12:00 PM): application of Interpreting Indicators of Rangeland Health, reference sheet development, ecological site identification, and supplementary quantitative measurements

Instructors: Fee Busby (Utah State), Jeff Herrick (ARS), Mike Pellant (BLM), Dave Pyke (USGS), and Pat Shaver (NRCS)

Registration (required, no cost): DOI employees: https://doilearn.doi.gov/; others: http://doilearn.doi.gov

Related course at IGC-IRC, Inner Mongolia, China (fee applies): Inventory, Assessment, and Monitoring of the Ecological Status of Rangelands: A Practical Approach 24-28 June 2008

Registration instructions and more information for all three courses: http://usda-ars.nmsu.edu/JER/Monit_ Assess/monitoring.htm > Courses

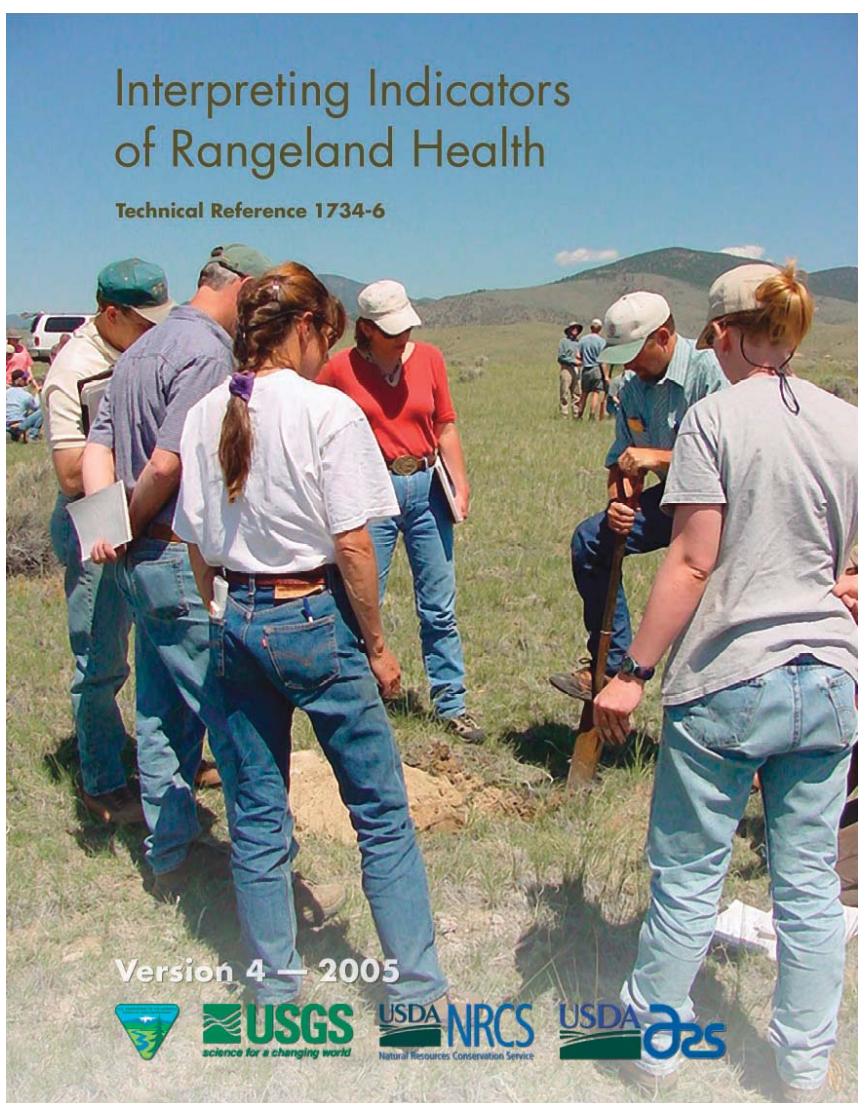

